\title{
Children road traffic injuries in Poland
}

\begin{abstract}
Road traffic injuries are the leading cause of child mortality in Poland, resulting in more deaths than cancer or birth defects. We present the main problems of road safety and the nature of the causes and consequences of accidents among children based on the World Health Organization Report. Children injuries are one of the main problems in modern medicine requiring vigorous and preventive actions. Children of all ages should be intensively involved in the educational activities related to road safety. Raising awareness concerning the risks associated with children's participation in traffic as well as the awareness of parents and carers can greatly reduce the number of accidents.
\end{abstract}

Keywords: road accidents, children's injuries, health promotion.

DOI: $10.1515 /$ pjph-2017-0010

\section{INTRODUCTION}

In general, children are very active. They exhibit a desire for a constant movement, which is necessary for their healthy development. Running, jumping, cycling, skiing, skating etc. are very healthy activities, however, sometimes falls and trauma terminate them. The reason for that are the facts that children do not posses proper movement coordination, are not mature to understand and predict the negative consequences and are not always equipped with protective gear, like helmets. Furthermore, drinking alcohol and driving a car in a very early stage of life also may lead to unwanted medical outcomes such an injuries. Those among children are considered to be a growing global public health problem. According to the WHO's opinion expressed in "the World Report on Child Injury Prevention", hundreds of thousands of children every year suffer from injuries and millions of others have to deal with the consequences of drink - driving. The list of unintentional injuries constituting the major problems listed by the WHO include: road traffic injuries, drownings, burns, falls and poisoning. As every child in the world matters and has the right to save environment and be protected from injury and violence (Convention on the Rights of the Child), there are many problems to be approached by a public health sector to reduce child injuries throughout the world effectively [1].

\section{Road accidents involving children - a world-wide perspective}

One of the biggest problems in terms of unintentional injuries among children are road traffic injuries, as roads have always constituted a dangerous place as far as children are concerned. It is due to the fact that the road environment is constructed in most cases without taking into account children's needs. Additionally, children may live near the roads or play on them. There are more factors making children especially prone to accidents, what is more, neither roads nor cars are fitting their needs - they are designed for adults. All those issues make the situation multifaceted for the young generation of users. The annual number of road casualties with injury or disability accounts for around 10 million children worldwide. They may enter a road as pedestrians, bicyclist, young car drivers, car occupants, motorcycle riders and passengers or public transport passengers. In details, accidents are the leading cause of death in children aged 15-19; the second leading cause in children aged 5-14 are also the leading cause of disability among children in general. Disabled children require long-term care and their quality of life is often poor. All in all, traffic- related deaths account for nearly $2 \%$ of all deaths among children. When analyzing gender, boys are more likely to be involved in road traffic accidents than girls. The death rate for boys is 13.8 per 100000 , for girls 7.5 per 100000 . Globally, the percentage of road fatalities is 10.7 per 100000 and it increases with age. About 33\% of all child fatalities around the world are pedestrians, while $65 \%$ are car occupants, bicycle or motorcycle riders (mainly middle income and high income countries). As for cyclists, they constitute $3-15 \%$ of children injured in traffic collisions and $2-8 \%$ of child traffic-related fatalities worldwide. Moreover, young drivers constitute a great problem: crashes involving this age group account for $20-30 \%$ of all road traffic fatalities; the main

\footnotetext{
${ }^{1}$ Faculty of National Security and Logistics, Polish Air Force Academy, Deblin, Poland

2 Department of Disaster Medicine, Medical University of Warsaw, Poland

${ }^{3}$ Emergency Medicine Unit, Medical University of Lublin, Poland

${ }^{4}$ National Medicines Institute, Warsaw, Poland

${ }^{5}$ Department of General and Transplantation Surgery, Medical University of Warsaw, Poland
} 
causative factors are: drink - driving, speeding, lack of fastening seatbelts, distraction caused by mobile phones, the presence of other adolescents and violation of traffic rules. In most age groups, except for the 15-19, road - traffic fatalities are greater in low-income countries and middle-income countries than in high-income countries. Figure 1 presents the nature of road traffic injury sustained by children in four low-income countries in 2013 [1].

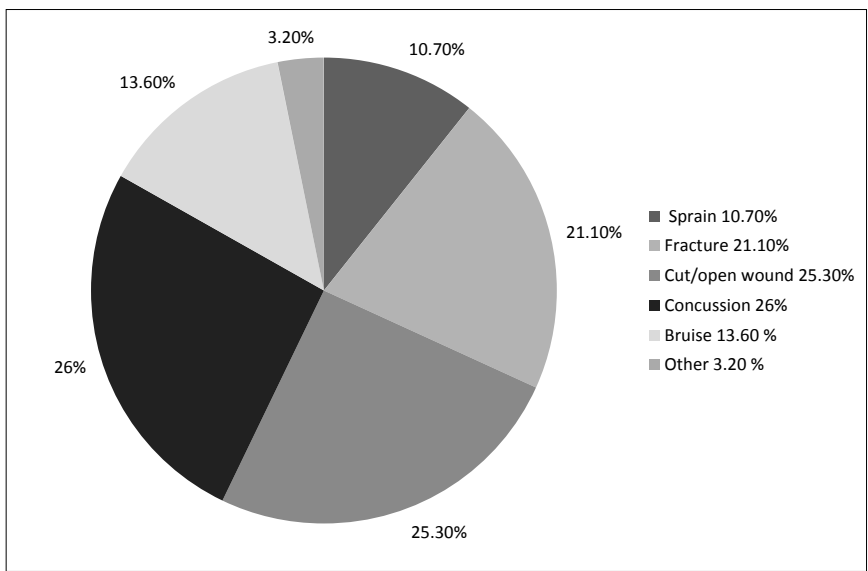

FIGURE 1. Injuries sustained by children recorded by an emergency department as a result of a road traffic crash in four countries in 2013.

Source: World report on child injury prevention, WHO, Geneva.

Multiple traumas have also been reported in approximately $10-20 \%$ of children involved in road traffic events. Inadequate pre-hospital and emergency care in many low -income and middle - income countries (lack of first-aid services and trained personnel, unsafe models of transportation to emergency care, long delay between the time of injury and reaching hospital, the absence of triage system etc.) only augment the issue. There are also risk factors specifically relating to children's physics. Children are less visible on a road than adults, have difficulties seeing over vehicles and discerning the distance of vehicle from the sound of its engine. Even more, they lack knowledge, skills and concentration to behave safely on the roads. When hit by a vehicle, their small posture make them proner to severe injuries such as head or neck injury - Table 1 [2].

There are also certain environmental factors that contribute to the number of road traffic injuries among children: sites with a volume of traffic exceeding 15.000 motor vehicles per day, long by-pass roads which encourage high speed, lack of playgrounds resulting in children playing on roads, lack of facilities to separate road users from driving environment, street vendor businesses and lack of safe, efficient public transportation system.

Road traffic injury results in a great number of consequences for those directly involved, as well as for national economy. The direct and indirect costs include: permanent disabilities (benefit payments), school absence, medical care, rehabilitation, legal costs, vehicle repair costs and lost of income in case of parents resulting from absence at work to care for the child.

Road traffic accidents have also a great impact on children's mental health. It includes: phobias, post-traumatic stress disorder, anxiety and behavioral problems [2].

Measures should be undertaken to prevent pediatric injuries. First, changing the philosophy from "children should adapt their behavior" to "children's need should be taken into account" seems to be the crucial one. An improved transport and a suitable road infrastructure, as well as creation of safe environment for children are among the basic preventing strategies. The following factors (primary prevention) should be taken into account in order to reduce the number of road- traffic injuries among children: reducing speed limits especially in residential areas and around schools to $30 \mathrm{~km} / \mathrm{h}$, physical separation of two-wheelers from other road users, modifications in vehicle designs (for example alcohol interlock system, audible alarms for reversing), car safety equipment (car restraints, seat - belts over the age of 10 or above $150 \mathrm{~cm}$ of height), bicycle helmet (reduces the risk of head and severe brain injury by $63-88 \%$ ), motorcycle helmet (by $72 \%$, and risk of death by 39\%), motor vehicle licensing (raising the age limit for all powered two-wheelers aged 16-18 years), drunk - driving laws (setting lower blood alcohol concentration limits for younger drivers, raising the legal drinking age, undertaking random breath-testing), daytime running lights for motorcyclist, teaching young children road safety behavior, etc. Some of these strategies have already brought visible changes in the reduction of traffic - related deaths in some countries (child restraint reduce death among infants by $70 \%$ and among small children aged 1-4 years, by 54\%). There are certain measures that can further improve those good data, like introducing and enforcing mandatory law on child restrain use, promoting those laws among parents, public awareness campaigns, etc.[2].

TABLE 1. Haddon Matrix applied to the risk factors for road traffic crash injuries among children.

\begin{tabular}{|c|c|c|c|c|}
\hline & Child factors & Vehicle and safety equipment & Physical environment & Socioeconomic environment \\
\hline Pre-event & $\begin{array}{l}\text { Age; gender; lack of supervision; } \\
\text { risk-taking; impulsive behaviour; } \\
\text { disobedience; lack of police } \\
\text { enforcement. }\end{array}$ & $\begin{array}{l}\text { Lack of vehicle roadworthiness; } \\
\text { poor lighting; poor state of brakes; } \\
\text { speeding; overloading }\end{array}$ & $\begin{array}{l}\text { Poor road design; lack of public } \\
\text { transport; no enforcement of speed } \\
\text { limits; no safety barriers; lack of } \\
\text { alcohol laws; poor infrastructure } \\
\text { for pedestrian safety }\end{array}$ & $\begin{array}{l}\text { Poverty; single-parent family; } \\
\text { large family size; poor maternal } \\
\text { education; lack of risks aware- } \\
\text { ness among caregivers, childcare } \\
\text { providers and educators. }\end{array}$ \\
\hline Event & $\begin{array}{l}\text { Height and physical development } \\
\text { of child; lack of equipment } \\
\text { to protect occupants, or equip- } \\
\text { ment improperly used; underlying } \\
\text { conditions in child. }\end{array}$ & $\begin{array}{l}\text { Child restraints and seat-belts not } \\
\text { fitted or incorrectly used; bicycle } \\
\text { and motorcycle helmets not used; } \\
\text { poor design of vehicle } \\
\text { for protection in crashes; } \\
\text { no rollover protection. }\end{array}$ & $\begin{array}{l}\text { Roadside objects such as trees } \\
\text { and poles. }\end{array}$ & $\begin{array}{l}\text { Lack of safety culture in the car } \\
\text { and on the road. }\end{array}$ \\
\hline Post-event & $\begin{array}{l}\text { Child's lack of resilience; child's } \\
\text { general condition; lack of access } \\
\text { to appropriate health care; } \\
\text { post-injury complications. }\end{array}$ & $\begin{array}{c}\text { Difficult access to victim; lack } \\
\text { of trained health-care and rescue } \\
\text { workers. }\end{array}$ & $\begin{array}{l}\text { Lack of availability of adequate } \\
\text { pre-hospital care, acute care and } \\
\text { rehabilitation. }\end{array}$ & $\begin{array}{c}\text { Lack of supporting injured people; } \\
\text { no first aid given at the accident } \\
\text { scene. }\end{array}$ \\
\hline
\end{tabular}

Source: World report on child injury prevention, WHO. 
As for secondary and tertiary prevention measures, there are also other factors of a great importance such as: strengthening the emergency medical services - pre-hospital care, hospital care (trauma centers) and rehabilitation centers. The fact that efficient and effective pre-hospital care can save many lives is a well-known factor. It requires emergency vehicles to be equipped with supplies and medical devices for children (airway tubes, cervical collars, blood pressure cuffs, etc). The pre-hospital employees need to be trained in taking care of pediatric patients. Trauma centers are the second stage at which the life of an injured child can be saved. Therefore, trained and skilled personnel and adequate equipment are necessary to evaluate and manage an injured child. As for rehabilitation - the improved services in health-care facilities and improved access to community - based rehabilitation are the most important factors. Table no. 2 presents a list of important interventions, which should be implemented in order to reduce the number of road traffic injuries.

TABLE 2. Key strategies to prevent road traffic injuries among children.

\begin{tabular}{|c|c|c|c|c|c|}
\hline Strategy & 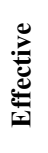 & م. & 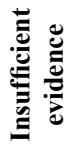 & 苞 & ב̇ \\
\hline $\begin{array}{l}\text { Introducing (and enforcing) minimum } \\
\text { drinking-age laws }\end{array}$ & & & & & \\
\hline $\begin{array}{l}\text { Setting (and enforcing) lower blood alcohol } \\
\text { concentration limits for novice drivers } \\
\text { and zero tolerance for offenders }\end{array}$ & & & & & \\
\hline $\begin{array}{l}\text { Utilizing appropriate child restraints } \\
\text { and seat-belts }\end{array}$ & & & & & \\
\hline Wearing motorcycle and bicycle helmets & & & & & \\
\hline $\begin{array}{l}\text { Forcing a reduction of speed } \\
\text { in the neighbourhood of schools, } \\
\text { residential areas, play areas }\end{array}$ & & & & & \\
\hline Separating different types of road users & & & & & \\
\hline $\begin{array}{l}\text { Introducing (and enforcing) daytime } \\
\text { running lights for motorcycles }\end{array}$ & & & & & \\
\hline $\begin{array}{l}\text { Introducing graduated driver licensing } \\
\text { systems }\end{array}$ & & & & & \\
\hline
\end{tabular}

\begin{tabular}{l}
\hline $\begin{array}{l}\text { Implementing designated driver } \\
\text { programmes }\end{array}$ \\
\hline Increasing the visibility of pedestrians \\
\hline $\begin{array}{l}\text { Introducing campaigns in schools } \\
\text { on the dangers of drink-driving }\end{array}$
\end{tabular}

Conducting school-based driver education

Putting babies or children on a seat

with an air bag

Licensing novice teenage drivers

Source: World report on child injury prevention, WHO, Geneva.

\section{Road accidents involving children in Poland}

135.438 traffic - related injuries involving children aged 0-14 years took place in Poland between the years 2000-2014. In those accidents 4.334 children died and 141.009 were injured. As shown above, the highest number of reported casualties is visible among children aged between 7 and 14 years [3]. The children, who were injured in the traffic accidents, were primarily pedestrians. The consequences of injuries sustained as pedestrians are the leading cause of death in children between 5 and 9 years of age. Mortality rate for this type of injury is $3.6 \%$, which is a high value compared with the mortality rate of children - passengers between $0.5-1 \%$ [4]. Mostly children of school age, who suddenly run out on the roadways before the incoming vehicle, suffer. Most children are victims in urban areas, but also towns come close to that number. In Poland, many roads have no sidewalks but lots of sharp bends which increase the risk of an accident. The most common perpetrators of pedestrians - children are young drivers under 30 years of age [3]. A child who has completed the seventh year of life may - in accordance with the law - enter a road without adult supervision. According to the Police Headquarters, most accidents involving children take place on the route home - school - home [3]. In Poland 7 - year-old children often go to school without adult supervision, frequently for several kilometers. This applies mainly to rural areas. However, in the cities child's route to school is often more dangerous. Sometimes they cross the street at unmarked points or without traffic lights [5]. According to Zuckerman children aged 6-12 years are twice more likely to become injured in a traffic accident than younger children. In this early school age children become more independent and communicationrelated injuries resulting from participation in road traffic while riding a bike, moped, skateboards and inline skates - are more common [6].

Among the school age victims of road accidents majority are pedestrians and car passengers, nevertheless cyclists also constitute a large group of victims. According to the Police Headquarters, almost half of child cyclists and motorcyclists involved in accidents did not obey the basic rules concerning road safety law that is giving way. Therefore, very often it was connected with the lack of knowledge concerning the law, as they did not know whose right of way it was [4].

Very vulnerable group of road users include youth aged 1517 years. In general, they are active road traffic users, as they move independently on the road, both as pedestrians, cyclists and moped drivers [4,7]. Whereas children aged $0-6$ years who are accident victims are primarily car passengers, pedestrians, and only a minor group of cyclists [8].

Most of the traffic accidents victims are boys or men below 25 years of age. The probability of deathfor them is three times greater than for young women. Researches of many authors show that in each age group of injuries there are more often boys than girls (this is particularly evident after 2 years of age) [9-11].

Anatomy and physiology of a child differs significantly from the anatomy and physiology of an adult. Knowledge of these differences is very important as they affect the symptoms, severity of injury and prognosis in childhood trauma [12]. Different proportions of child head and adults mean that the forces of impact during a traffic accident are proportionately larger in case of children head compared to adults. Severe head injury is observed in $80 \%$ of children who die from multiple organ injuries. In comparison, in adults, head injuries occur in approximately $50 \%$ of people suffering from multi-trauma. Head injuries in children, especially brain injuries cause a range of consequences remote in time from the time of the accident. These include early post-traumatic epilepsy (that comes up from one week to six months after the injury), late post-traumatic epilepsy (occurring more than 6 months after trauma), impaired mobility, mental retardation, posttraumatic syndrome, which includes headache, mental 
changes, sleep disorders, seizures. Quite often in children who suffered from serious brain injury, there are behavioral and emotional problems in the social area. They are manifested in forms of restlessness, infantile behavior, outbursts of anger or depressed mood and fears. When combining these disorders ,the outcomes of learning difficulties are associated with rapid mental fatigability, impaired concentration and memory and some children exhibit speech impediment [9]. For children involved in traffic accidents, the most common are head and neck injuries - approximately $60 \%$ of child casualties $[3,5,6]$. Furthermore, those injuries constitute the predominant cause of death among victims of road accidents (in all age groups and all categories of accidents -pedestrians, cyclists, passengers of motorbike vehicles, drivers and passengers of private cars and the victims of road accidents that are not defined precisely) [13]. Other injuries of child participants of road accidents include: extremities injuries (wounds, fractures), chest and abdomen injuries $[7,8]$.

The most common causes of road accidents involving children as pedestrians include: sudden intrusion of a child on the road, playing on roads and pavements, entering the road at the unauthorized point. Every road user has to employ a rule: the principle of trust. However, children are not capable of fully objective assessment concerning the situation on the road. Every time they cross the street they are exposed to danger. Additionally, children's behavior is very often spontaneous. When playing, children may forget the basic principles of safety (for example running onto the street to bring a ball).

Children are often blamed for the accident. It is worth noting, however, that the safe participation of children in road traffic is dependent on his mental and physical development. Child responses of central and peripheral nervous system, which is responsible for rational behavior in every situation ,to external stimuli are not yet sufficiently developed in the first years of primary school. Chidren at this stage have problems with distinguishing the relevant factors from irrelevant ones [5-7].

The causes of traffic accidents related to the successive stages of child development include: short height (children see less and are less visible to road users), lack of divided attention (children focus on only one task at a time - a conversation or mostly fun), acting on impulse, the desire to satisfy their own needs, short-term memory (the children quickly forget the last thing they saw), difficulty in locating the sound source (children react to only one sound which is important for them; the noises disperse and prevent children from concentrating on the traffic), difficulties with a proper assessment of distance and speed of the vehicle (child requires 3-4 seconds to distinguish a slowly moving car from a parked one), the narrow visual field (the child sees only what is in front of him and contrasts), difficulties in distinguishing left from right, failure to understand the risks in traffic, only partial knowledge of traffic rules (this does not mean, however, that they obey the known rules) [5$7,12,14]$. With age, the ability to perceive and evaluate the traffic situation is improving, nevertheless other threats emerge as overestimation of their abilities and skills to participate safely in traffic or the desire to peer rivalry. When a child reaches 10-12 years of age, he becomes more capable to deal with the traffic. Accidents involving children occur mostly in towns (at pedestrian crossings, public transport stops, intersections) on days off from school, weekends, holidays, on the route home - school - home, early afternoon, in the summer months $[4,5]$.
The incidence of traffic accidents varies depending on season. The most dangerous for children are the summer months from May to September, however mainly holiday months i.e. June, July and August. In the summer, visibility on the roads is much better than in autumn and winter, nevertheless trafficrelated fatalities in this period are several times more numerous among children. The reason behind it is that in the summer months the days are longer, therefore children spend more time outdoors, cycling, skating, jogging and playing football. They use road not only on the route home - school and back, but they go to playgrounds as well. Holidays are also a time of travelling with parents. Children are involved mainly in accidents as car passengers [4-6,8,9].

The most important role in the prevention of traffic accidents is assigned to parents and guardians of children. They are responsible for preparation of child to participate in traffic responsibly. Parents are the first teachers and have the greatest potential impact. An example of the parents is the most effective way children learn proper behavior. Parents and caregivers should refrain from any mistakes, recklessness, disregard for traffic rules, because the child may take such action as a norm or accept them subconsciously $[9,15]$.

Children are not "miniatures of adults". Their different anatomical structure, psychological maturity, variety of interests, need for fun and safe passage to school mean that children require special security measures. The ways to reduce the risks for children on the roads include, inter alia: setting a good example of compliance with traffic rules by adults, providing an adequate care to the youngest children (especially during the holidays), prohibition of playing on the nearby roads, creation of safe playgrounds, waking up the child early enough not to hurry to school, dressing children in bright visible clothes, especially during autumn and winter, equipping children with reflective elements (reflective elements secured on a child make them visible from a distance, giving the driver time to reduce the speed), supervising children under the age of 12 years on their way to school, developing collision-free cycle paths (especially in cities) and the obligation to equip the bike with lights and reflective elements, the mandatory use of helmets by cyclists and motorcyclists, fastening seat belts in the car even on the shortest route, absolutely correct use of child safety seats $[5,12,15]$.

A huge role in reducing the number of injuries among children plays their education. Preschool age is the period in which the child is growing rapidly, is interested in the world and exhibits curiosity and on this basis their knowledge and skills concerning the participation in traffic should be built. Communication Education is also an investment for the future. By doing that, not only well-behaved and safe future drivers can be educated, but above all well-informed citizens who are attached to the appropriate values and perceive needs of others, not just in traffic.

\section{CONCLUSION}

The modern world is full of various risks, which often concern children. Road accidents take more deaths than wars and also millions of people are being made disabled. Therefore, it is important for the children and adolescents safety to deal with that problem. Solving issues concerning child injuries is justified and necessary: improving outcomes of accidents, minimizing negative consequences of injuries and reducing 
their social costs. The number of traffic- related fatalities and casualties is not only a current problem in the world but it still has increasing tendency in the world, forecasted as $67 \%$ between 1990 and 2020. It is very important to accept the fact that an injury is not the result of random, uncontrolled factors. Injuries are preventable. The public health responsibilities are to collect data, analyze risk factors, make interventions and implement proven prevention methods. High risk of traffic accidents indicates that children of all ages should be intensively educated with the activities related to road safety. Injury as an issue to be solved should be discussed globally but also on national and local level. Each country should develop its own action plan involving different bodies and agencies.

\section{REFERENCES}

1. World Health Organization. Violence, Injury Prevention, and World Health Organization. Global status report on road safety 2013: supporting a decade of action. World Health Organization; 2013.

2. Peden MM. World report on child injury prevention. World Health Organization; 2008.

3. Polish National Police. [http://www.policja.pl] (17.11.2016).

4. National Road Safety Council [Internet]. [http://www.krbrd.gov.pl/en/.]

5. Goniewicz M, Nogalski A, Khayesi M, et al. Pattern of road traffic injuries in Lublin County, Poland. Cent Eur J Public Health. 2012;20(2):116.

6. Paradowska M. Comparison of Road Safety Policy Objectives in Poland and in the European Union. Transport Development Challenges in the Twenty-First Century: Springer; 2016. p. 103-23.

7. Prochowski L. Analysis of the impact of road category and day of the week on accident hazard in the road transport of goods in Poland. J KONES. $2013 ; 20$.

8. Kisilowski J, Zalewski J. Chosen aspects of analysis of road traffic safety in Poland between 1995 and 2008. J KONBIN. 2010;14:409-20.

9. Sendek-Matysiak E. Analysis of the Relation Between Assessing Own as Well as Other People's Driving Skills and Causing Road Collisions and Accidents. Contemporary Challenges of Transport Systems and Traffic Engineering. Springer International Publishing, 2017. p.127-35.

10. Holló P, Eksler V, Zukowska J. Road safety performance indicators and their explanatory value: A critical view based on the experience of Central European countries. Saf Sci. 2010;48(9):1142-50.

11. Nagurnas S, Mitunevičius V, Unarski J, Wach W. Evaluation of veracity of car braking parameters used for the analysis of road accidents. Transport. 2007;22(4):307-11.

12. Jurecki RS, Jaśkiewicz M. Analysis of road accidents in Poland over the last ten years. Zeszyty Naukowe.Akademia Morska w Szczecinie. 2012(32 (104) z. 2):65-70.

13. Lasota D, Staniszewska A, Tarchalska-Kryńska B, et al. Insobriety and the risk of death in traffic accident. J Edu Health Sport. 2015;5:6.

14. Dworkin PH. Pediatria. Wrocław: Wydawnictwo Urban \&Partner; 2000.

15. Goniewicz, K, Goniewicz, M, Pawłowski W, et al. Eur J Trauma Emerg Surg. 2016;42:433.

\section{Corresponding author}

Krzysztof Goniewicz,

81 Zwirki i Wigury St., 02-091 Warsaw

tel.: +48 (0-22) 5720545,5720536

fax: $+48(0-22) 5720543$

E-mail: krzysztof.goniewicz@wum.edu.pl 